\title{
TEORIA DAS REPRESENTAÇÕES SOCIAIS E TEORIAS DE GÊNERO
}

\author{
ANGELA ARRUDA \\ Universidade Federal do Rio de Janeiro \\ aarruda@inx.com.br
}

RESUMO

Este texto objetiva oferecer uma breve panorâmica da teoria psicossociológica das representaçôes sociais, estabelecendo algumas pontes com as teorias feministas de gênero. Nesse sentido, percorre as origens e fundamentos da teoria de Moscovici, as suas variações e alguns pontos de convergência com as teorias feministas.

PSICOLOGIASOCIAL-MOSCOVICI, SERGE-TEORIAFEMINISTA-RELAÇÕESDEGÊNERO

\section{ABSTRACT}

SOCIAL REPRESENTATION THEORIESAND GENDER THEORY. Thistext intends to offer a brief panorama of the social psychological theory of social representations and establishes some links with the feminist theories of gender. It will thus present the origin and the basis of Moscovici's theory, its variations and some converging points in relation to feminist theories.

SOCIAL PSYCHOLOGY_MOSCOVCI, SERGE_FEMINIST THEORY_GENDER 
Nos últimos anos, o conceito de representação social tem aparecido com grande freqüência em trabalhos de diversas áreas, o que leva muitas vezes à indagação sobre o que será, afinal, algo de que tanto se fala.

Com efeito, este conceito atravessa as ciências humanas e não é patrimônio de uma área em particular. Ele tem fundas raízes na sociologia, e uma presença marcante na antropologia e na história das mentalidades. Dessa forma, antes de mais nada convém explicitar o lugar de onde falo, para situar a que me refiro.

A partir dos anos 60, com o aumento do interesse pelos fenômenos do domínio do simbólico, vemos florescer a preocupação com explicações para eles, as quais recorrem às noções de consciência e de imaginário. As noções de representação e memória social também fazem parte dessas tentativas de explicação e irão receber mais atenção a partir dos anos 80 . Como vários outros conceitos que surgem numa área e ganham uma teoria em outra, embora oriundos da sociologia de Durkheim, é na psicologia social que a representação social ganha uma teorização, desenvolvida por Serge Moscovici e aprofundada por Denise Jodelet. Essa teorização passa a servir de ferramenta para outros campos, como a saúde, a educação, a didática, o meio ambiente, e faz escola, apresentando inclusive propostas teóricas diversificadas.

É, pois, da perspectiva psicossocial que parte a minha exposição. $\bigcirc$ objetivo deste texto é apresentar uma panorâmica da teoria psicossociológica das representações sociais, estabelecendo algumas pontes com as teorias feministas de gênero.

A psicologia social aborda as representações sociais no âmbito do seu campo, do seu objeto de estudo - a relação indivíduo-sociedade - e de um interesse pela cognição, embora não situado no paradigma clássico da psicologia: ela reflete sobre como os indivíduos, os grupos, os sujeitos sociais, constroem seu conhecimento a partir da sua inscrição social, cultural etc., por um lado, e por outro, como a sociedade se dá a conhecer e constrói esse conhecimento com os indivíduos. Em suma, como interagem sujeitos e sociedade para construir a realidade, como terminam por construí-la numa estreita parceria - que, sem dúvida, passa pela comunicação. Mas isso só pode acontecer a partir de uma certa conjuntura científica, como passo a enunciar brevemente.

\section{AS REPRESENTAÇÕES SOCIAIS: PONTOS DE PARTIDA}

A obra seminal de Moscovici, La Psychanalyse, son image, son public, que contém a matriz da teoria, surge em 1961 na França, causando espécie nos meios intelectuais pela novidade da proposta. Entretanto, foi um rápido momento de im- 
pacto que não produziu desdobramentos visíveis. A perspectiva moscoviciana permaneceu encerrada no Laboratório de Psicologia Social da École de Hautes Études en Sciences Sociales, em Paris, e nos laboratórios de colegas como Claude Flament, Jean Claude Abric, no sul da França, e outros também interessados por ela, de forma mais dispersa, na Europa. A teoria aparentemente não vinga de imediato, fazendo sua reaparição com força total no início dos anos 80.

Como outras contribuições importantes, ela surge antes do seu tempo, contrariando o paradigma dominante na época, na Psicologia e nas Ciências Sociais. Na Psicologia, o enfoque sintetizado no behaviorismo, com o imperativo experimental a estabelecer os limites do que era considerado científico, ainda prevalecia, embora seu longo ocaso já houvesse iniciado. A pesquisa de Moscovici, voltada para fenômenos marcados pelo subjetivo, captados indiretamente, cujo estudo se baseava em metodologias inabituais na psicologia da época e dependia da interpretação do pesquisador, fugia aos cânones da ciência psicológica normal de então. Seria preciso esperar quase vinte anos para que o degelo do paradigma permitisse o despontar de possibilidades divergentes.

Nas ciências sociais, a presença de uma determinada leitura do marxismo tendia a atrelar o desenvolvimento superestrutural à infraestrutura, deixando poucas brechas para a autonomia desta, até que Althusser lançasse os Apare/hos ideológicos do Estado (Jodelet, 2002). É a partir dessa inflexão que foi possível encarar com mais tranqüilidade a diversidade da produção de pontos de vista dentro de uma mesma classe social, afrouxando o determinismo da infraestrutura.

Talvez se pudesse acrescentar a esta análise o fato de que o período que vai do fim dos anos 60 ao início dos 80 traz à cena "novos personagens" (Sader, 1988). São atores sociais que explicitam energicamente suas demandas, propondo à ciência novos conceitos a incorporar na análise da realidade, como o de gênero, ou levando-a a repensar categorias para poder levá-los em consideração - como é o caso da noção de novos movimentos sociais.

Se considerarmos que a ciência não acontece dentro de uma bolha, isolada da sociedade, podemos perceber como o quadro que a cerca incidirá também sobre a sua produção, como tentei rapidamente indicar. O próprio Moscovici, fazendo eco às reivindicações estudantis do movimento de 1968, afirma que a Psicologia Social não podia fechar-se numa torre de marfim, alheia às questões colocadas pela sociedade (Moscovici, 1973).

A Teoria das Representações Sociais - TRS - operacionalizava um conceito para trabalhar com o pensamento social em sua dinâmica e em sua diversidade. Partia da premissa de que existem formas diferentes de conhecer e de se comuni- 
car, guiadas por objetivos diferentes, formas que são móveis, e define duas delas, pregnantes nas nossas sociedades: a consensual e a científica, cada uma gerando seu próprio universo. A diferença, no caso, não significa hierarquia nem isolamento entre elas, apenas propósitos diversos. $\bigcirc$ universo consensual seria aquele que se constitui principalmente na conversação informal, na vida cotidiana, enquanto o universo reificado se cristaliza no espaço científico, com seus cânones de linguagem e sua hierarquia interna. Ambas, portanto, apesar de terem propósitos diferentes, são eficazes e indispensáveis para a vida humana. As representações sociais constroem-se mais freqüentemente na esfera consensual, embora as duas esferas não sejam totalmente estanques. $\bigcirc$ quadro a seguir tenta sintetizar um pouco do que foi explicitado, acrescentando a visão corrente de que no universo consensual aparentemente não há fronteiras, todos podem falar de tudo, enquanto no reificado só falam os especialistas. De acordo com ele, seríamos todos "sábios amadores", capazes de opinar sobre qualquer assunto numa mesa de bar, diferentemente do que ocorre nos meios científicos, nos quais a especialidade determina quem pode falar sobre o quê.

\author{
Universos consensuais \\ Indivíduo, coletividade: \\ opusproprium \\ NÓS \\ Sociedade $=$ grupo de iguais, todos \\ podem falar com a mesma \\ competência
}

Universos consensuais

Sociedade de "amadores", curiosos:

conversação, cumplicidade, impressão de igualdade, de opção

e afiliação aos grupos

Conhecimento parece exigência de comunicação $\rightarrow$ alimentar e

consolidar o grupo

- resistência à intrusão

Representações sociais

- senso comum, consciência

coletiva

- acessível a todos; variável

\section{Universos reificados}

\section{opus alienum}

ELES

Sociedade $=$ sistema de papéis e classes diferentes $\rightarrow$ direito à palavra é desigual: experts

Universos reificados

Sociedade de especialistas: especialidade $\rightarrow$ grau de participação normas dos grupos $\rightarrow$ propriedade do discurso e comportamento Unidade do grupo por prescrições globais, não por entendimentos recíprocos

- divisão por áreas de competência

\section{Ciência}

- retratar a realidade independente de nossa consciência

- estilo e estrutura frios e abstratos 
○ que Moscovici avança, com esta sistematização, é uma reabilitação do senso comum, do saber popular, do conhecimento do cotidiano, o conhecimento "pré-teórico" de que falam Berger e Luckmann (1978). Se antes este saber era considerado confuso, inconsistente, equivocado (opinião sobre a qual tanto o iluminismo quanto o marxismo vão coincidir, acreditando que a superação do erro e da ignorância se dava pela via do pensamento científico). Moscovici e Markova questionam a racionalidade científica e insurgem-se contra a idéia de que as pessoas comuns, na vida diária, pensam irracionalmente, ao afirmarem que:

Na verdade, pode-se dizer que são os intelectuais que não pensam racionalmente, já que produziram teorias como o racismo e o nazismo. Acreditem: a primeira violência anti-semita ocorreu nas universidades, não nas ruas. (I998, p.375)

A biografia de Moscovici (1997) confirma que o motor da sua pesquisa se inscreveu na história da sua vida, testemunha da opressão nazista durante a Segunda Guerra mundial. Ela levou-o à formulação da pergunta que o persegue até hoje: por que a fé remove montanhas? Como é possível que os seres humanos se mobilizem a partir de algo que aparentemente supera a razão? Como é possível que sejam conhecimentos práticos a base para que eles vivam suas vidas?

A resposta a tais perguntas gerou sua obra inicial, na qual começamos a perceber um desmonte de velhas divisórias tão conhecidas da ciência psicológica: a fronteira entre razão e senso comum, razão e emoção, sujeito e objeto. A realidade é socialmente construída e o saber é uma construção do sujeito, mas não desligada da sua inscrição social. Assim, Moscovici propõe uma psicossociologia do conhecimento, com forte apoio sociológico, mas sem desprezar os processos subjetivos e cognitivos.

Após esta rápida descrição sobre o surgimento da TRS, já posso lançar algumas pontes em direção às teorias feministas.

\section{FEMINISMO E REPRESENTAÇÕES SOCIAIS: TEORIAS EMERGENTES}

A primeira delas poderia ser considerada uma coincidência histórica: tanto a TRS quanto as teorias feministas nascem na mesma conjuntura de degelo dos paradigmas, para a qual concorrem. Na verdade, trata-se de um zeitgeist que percorre as ciências, marcado pela necessidade de novos instrumentos conceituais que se afinem com os tempos que correm. É o que Boaventura de Sousa Santos ( 1989) denominou transição paradigmática, que favorece a abertura para teorias emergentes. Elas guardam algumas afinidades entre si, que proponho perfilar em 
três grandes dimensões: a dos campos de saber, a conceitual-metodológica e a epistemológica.

A dimensão do desenvolvimento dos campos de saber refere-se a propostas que se integrarão em campos de saber seguindo certas características e o desenvolvimento que delas advém:

- O fato de que essas teorias não surgem desligadas das realidades concretas, mas em estreita sintonia com elas, a exemplo do conceito de gênero, nascido nas entranhas do movimento feminista.

- Não se instalam com tranqüilidade nem em harmonia nas áreas em que se inserem, mas em conflito com elas, estabelecendo um certo dissenso nessas áreas. Explicitam, assim, uma vez mais, o quanto os campos de saber são também campos de disputa, como observou Bourdieu (1 983) e o quanto as propostas dissidentes concorrem para a renovação desses campos, capitaneadas por minorias ativas (Moscovici, 1979).

- São favorecidas pela transição paradigmática, que abre brechas para suas incursões, nem sempre aceitáveis para os padrões de ciência da época e as normas dos campos científicos que penetram.

- Vivem um período de latência entre o surgimento das idéias inaugurais e o desenvolvimento da sua aplicação, e o advento da conseqüente visibilidade. No caso do gênero, o conceito, remodelado pelo pensamento feminista nos anos 80 (Scott, 1988; Rubin, 1979), como o de representação social por Moscovici, vive um lapso de tempo até ser incorporado às ciências sociais.

Quanto à dimensão conceitual de tais teorias, vê-se que elas apresentam características comuns no que se refere aos objetos a que se aplicam e aos métodos mais adequados à sua abordagem:

- destinam-se a revelar e/ou conceituar aspectos de objetos até então subvalorizados pela ciência, considerados como menores (a mulher, o senso comum);

- tomam seus temas/objetos ao mesmo tempo como processo e produto, o que exige abordagens mais dinâmicas e flexíveis;

- em conseqüência - e considerando que o método decorre das características do objeto e da teoria adotada, e busca a reunião desses dois para 
gerar o conhecimento - trabalham com tais objetos/temas de formas não obrigatoriamente canônicas, ousando metodologias criativas, nem sempre específicas daquela área disciplinar, e nem sempre consideradas legitimamente científicas na área.

A dimensão epistemológica abraça perspectivas do conhecer divergentes daquelas que informavam o paradigma ainda dominante. Nesse sentido, as teorias feministas e a TRS

- tecem uma crítica ao binarismo que antepõe natureza e cultura, razão e emoção, objetivo e subjetivo, pensamento e ação, ciência e senso comum. Dessa forma, afirmam a importância das dimensões subjetiva, afetiva, cultural na construção do saber e nas ações humanas, e a importância de considerá-las na construção do conhecimento e no fazer científico;

- propõem teorias relacionais, em que não se pode conhecer sem estabelecer relação entre o tema/objeto e o seu contexto. Gênero é uma categoria relacional, na qual, ao se levar em conta os gêneros em presença, também se consideram as relações de poder, a importância da experiência, da subjetividade, do saber concreto. Da mesma maneira, a TRS não separa o sujeito social e o seu saber concreto do seu contexto, assim como a construção desse saber não pode se desvincular da subjetividade. Vemos aqui como essas novas propostas se aproximam do pensamento complexo de que nos fala Morin ( 1985, 1999), ao voltarem-se para abordagens apoiadas em redes de fatores que permitam dar sentido aos fenômenos que se quer estudar.

Essas dimensões (e certamente outras, não sistematizadas aqui) indicam, portanto, que estas teorias estão reabilitando o conhecimento concreto, a experiência vivida, e reconhecendo a possibilidade de diversas racionalidades, o que é adequado às características das multifacetadas sociedades e grupos sociais contemporâneos e às características da forma de conhecer e lidar com o saber nessas sociedades, em que grupos diferentes têm visões diferentes de um mesmo objeto sem que a diferença implique obrigatoriamente desigualdade. Sociedades mais quais é preciso entender a diferença como especificidade, como nos ensinam os movimentos de grupos minoritários. 
A representação social seria uma forma de conhecer típica dessas sociedades, cuja velocidade vertiginosa da informação obriga a um processamento constante do novo, que não abre espaço nem tempo para a cristalização de tradições, processamento que se esteia no olhar de quem vê. A representação social, portanto, não é uma cópia nem um reflexo, uma imagem fotográfica da realidade: é uma tradução, uma versão desta. Ela está em transformação como o objeto que tenta elaborar. É dinâmica, móvel. Ao mesmo tempo, diante da enorme massa de traduções que executamos continuamente, constituímos uma sociedade de "sábios amadores" (Moscovici, | 96 I), na qual o importante é falar do que todo o mundo fala, uma vez que a comunicação é berço e desaguadouro das representações. Isto indica que o sujeito do conhecimento é um sujeito ativo e criativo, e não uma tabula rasa que recebe passivamente o que o mundo lhe oferece, como se a divisória entre ele e a realidade fosse um corte bem traçado.

A seguir, exporei, no desenvolvimento do conceito de representações sociais, a base para a teoria, que fornece elementos para a compreensão da construção do saber prático.

\section{REPRESENTAÇÕES SOCIAIS : NASCE UMA TEORIA}

O paradigma cognitivista na psicologia, com sua notável expansão no estudo dos processos cognitivos (Roazzi, 1999), cercava-nos e estimulava a compreender fenômenos que escapavam ao seu cânone e limite. Para fazê-lo, tivemos que buscar fora da área recursos conceituais que nos possibilitassem essa aventura. Assim, Moscovici dirige-se ao conceito de representações coletivas de Durkheim para iniciar o percurso da teorização.

As representações coletivas em Durkheim apresentavam razoável estabilidade e um relativo estancamento no tocante às representações individuais, configurando-se em algo semelhante ao group mind, como diria Moscovici. Consistiam em um grande guarda-chuva que abrigava crenças, mitos, imagens, e também o idioma, o direito, a religião, as tradições.

Uma tal abrangência tornava porém o conceito pouco operacional. Apesar do seu interesse teórico, ele foi deixado de lado pela própria sociologia. A antropologia e, mais recentemente, a história das mentalidades abraçaram o conceito de representação, colocando sobre ele o foco do simbólico, por parte da primeira, e da memória, por parte da segunda. Tratava-se, note-se bem, de uma aplicação da noção em plagas distantes ou tempos passados. Graças a ela, o conceito sobrevi- 
veu e atestou seu interesse para as ciências humanas. Mas não foi além de um conceito, e permaneceu a lacuna no que se refere ao aqui e agora.

Moscovici vai proceder à remodelagem do conceito durkheimiano e assim buscar preencher essa lacuna. Ele caminhou guiado pela necessidade de atualizar o conceito, trazê-lo para as condições de hoje, de sociedades contemporâneas imersas na intensa divisão do trabalho, nas quais a dimensão da especialização bem como a da informaçãa tornaram-se componentes decisivas nas vidas das pessoas e dos grupos. Atualizar significava, ao mesmo tempo, tornar o conceito operacional para ser aplicável em sociedades com essas características, sociedades em que a velocidade da informação não Ihes outorga o tempo de sedimentar-se em tradição, na quais se impõe um processamento constante da novidade, nas quais se conhece por delegação, uma vez que ninguém tem acesso a todo o saber.

Operacionalizar o conceito, tal como se vê em La Psychanalyse, son image, son public (Moscovici, 196I), torná-lo teoria, exigiu que Moscovici recorresse a outros teóricos para apoiar sua perspectiva a respeito da construção do saber e do valor do saber prático. Vários autores foram consultados por Moscovici, mas reiterarei aqui resumidamente apenas os três mais pregnantes pela sua contribuição quanto aos processos de elaboração desse tipo de conhecimento: Piaget, LévyBruhl e Freud.

Piaget, por meio da sua contribuição a respeito do desenvolvimento do pensamento infantil - a forma como se estrutura e se configura -, mostra que ele se dá por imagens e também por corte-e-cola, juntando fragmentos do que a criança já conhece para formar uma configuração que traduza o que ela desconhece - o que muitas vezes se manifesta mais claramente para os adultos como o "falar errado" das crianças'. Mas também, a partir do julgamento moral, indicando a importância do contato com os adultos, primeiramente, e com outras crianças, mais tarde, para o desenvolvimento desse tipo de juízo e para a construção das regras pelas crianças. Lévy-Bruhl, por meio dos seus estudos sobre o pensamento místico, encontrado em povos distantes, aponta outras formas de lógica para pensar o mundo, basea-

I Em outra ocasião exemplifiquei tal fato com a maneira pela qual minha filha "repetia" a denominação da maçã caramelada em seus primeiros anos de fala: maçã de cara melada. Colegas me ofereceram exemplos semelhantes de corte-e-cola no qual as crianças montam uma denominação aproximada à dos adultos, recorrendo ao seu próprio conhecimento: balamarista, para malabarista (segundo a testemunha, para a criança era um tipo de bailarina que fazia aquelas evoluções com objetos); bargulhar para mergulhar (o mergulho sempre se dava batendo com a barriga na água, para a criança), e assim por diante. 
das em princípios diversos dos do pensamento ocidental, como o princípio de participação. Freud, com as teorias sexuais das crianças, mostra como elas elaboram e internalizam suas próprias teorias sobre questões fundamentais para a humanidade, teorias que carregam as marcas sociais da sua origem: a experiência vivida no seu grupo, na sociedade, e o diálogo com outras crianças, como as teorias que explicam o ato sexual.

Temos assim alguns fundamentos da construção do saber prático. Não mais em outra faixa etária ou em outras sociedades, mas aqui e agora, na idade adulta e em sociedades como as nossas. Moscovici (196I) sistematiza tais fundamentos, recorrendo a dois processos que são como duas faces de uma mesma moeda: um, denominado objetivação, esclarece como se estrutura o conhecimento do objeto. Ele trabalha em três etapas: primeiro, como a criança de Piaget, seleciona e descontextualiza elementos do que vai representar, operando assim um enxugamento do excesso de informação, uma vez que não é possível lidar com o conjunto da informação transmitida. Esta sofre cortes baseados na nossa informação prévia, na experiência (como as crianças de Freud) e nos nossos valores. Uma vez feitos os recortes, recosturam-se os fragmentos num esquema que se torna o núcleo figurativo da representação, o qual, segundo Jodelet, tende a apresentar um aspecto imagético, como entre os adultos que também pensam com imagens. Tal aspecto constitui a quintessência da representação, seu cerne. Procedendo assim, aquele objeto que era misterioso foi devidamente destrinchado, recomposto, e agora torna-se algo efetivamente objetivo, palpável, passa a nos parecer natural. Chegamos à fase da naturalização, e completou-se o ciclo da objetivação. É aqui que se cristaliza o complexo, por exemplo, como naturalização do esquema figurativo da psicanálise - algo tão tangível que pareceria ser carregado no bolso das pessoas, ao afirmarem: "Ela tem um complexo comigo"; "ele tem um complexo de inferioridade". E o inconsciente, que pode estar calmo ou agitado (Moscovici, I96I), como uma pessoa.

Ancoragem é o outro processo, aquele que dá sentido ao objeto que se apresenta à nossa compreensão. Trata-se da maneira pela qual o conhecimento se enraíza no social e volta a ele, ao converter-se em categoria e integrar-se à grade de leitura do mundo do sujeito, instrumentalizando o novo objeto. $O$ sujeito procede recorrendo ao que é familiar para fazer uma espécie de conversão da novidade: trazê-la ao território conhecido da nossa bagagem nocional, ancorar aí o novo, o desconhecido, retirando-o da sua navegação às cegas pelas águas do não-familiar. É assim que as mulheres de baixa renda do interior da Paraíba vão referir-se à pílula contraceptiva como uma massinha podre que se vai juntando lá na mulher até que 
entope o canal dela (Arruda, 1993), uma forma de aproximar este invasor dos seus corpos por meio do universo familiar da domesticidade.

Moscovici considera que:

O processo social no conjunto é um processo de familiarização pelo qual os objetos e os indivíduos vêm a ser compreendidos e distinguidos na base de modelos ou encontros anteriores. A predominância do passado sobre o presente, da resposta sobre o estímulo, da imagem sobre a "realidade" tem como única razão fazer com que ninguém ache nada de novo sob o sol. A familiaridade constitui ao mesmo tempo um estado das relações no grupo e uma norma de julgamento de tudo o que acontece. (|96|, p.26)

Isso não significa contudo um conservadorismo rígido. Segundo a teoria em pauta, a representação social na verdade opera uma transformação do sujeito e do objeto na medida em que ambos são modificados no processo de elaborar o objeto. $\bigcirc$ sujeito amplia sua categorização e o objeto se acomoda ao repertório do sujeito, repertório o qual, por sua vez, também se modifica ao receber mais um habitante. A representação portanto, repito, não é cópia da realidade, nem uma instância intermediária que transporta o objeto para perto/dentro do nosso espaço cognitivo. Ela é um processo que torna conceito e percepção intercambiáveis, uma vez que se engendram mutuamente, como no caso do inconsciente "agitado" ou do complexo visível a olho nu.

Percebe-se, dessa maneira, o quanto essa teoria se diferencia de outras tradições da Psicologia Social, que sempre se ocuparam de fenômenos psicológicos como percepção, pensamento ou aprendizagem como tópicos isolados e tomados independentemente do que era percebido, pensado ou aprendido na sociedade e na cultura em que acontecem (Moscovici, 1989). É o que Farr (1994) identifica como a forma sociológica da psicologia social, em contraposição às formas psicológicas, hoje dominantes nos Estados Unidos.

\section{UM CONCEITO EM EXPANSÃO}

Essa discussão avançou para a compreensão do conceito de representação social desenhado pela teoria. Moscovici e Nemeth dirão que:

As representações sociais são conjuntos dinâmicos, seu statusé o de uma produção de comportamentos e relações com o meio, o de uma ação que modifica uns e outros, e não o de uma reprodução [...], nem o de uma reação a um estímulo exterior determinado. [...] são sistemas que têm uma lógica própria e uma lingua- 
gem particular, uma estrutura de implicações que se referem tanto a valores como a conceitos [com] um estilo de discurso próprio. Não as consideramos como opiniões sobre nem imagens de, mas como "teorias", como "ciências coletivas" sui generis, destinadas à interpretação e à construção da realidade. (1974, p.48)

Inúmeros autores propuseram sua própria definição, em razão do seu foco de interesse e da sua posição teórica. Por exemplo,

As representações sociais constituem uma espécie de fotossíntese cognitiva: metabolizam a luz que o mundo joga sobre nós sob a forma de novidades que nos iluminam (ou ofuscam) transformando-a em energia. Esta se incorpora ao nosso pensar/perceber este mundo, e a devolvemos a ele como entendimento mas também como juízos, definições, classificações. Como na planta, esta energia nos colore, nos singulariza diante dos demais. Como na planta, ela significa intensas trocas e mecanismos complexos que, constituindo eles mesmos um ciclo, contribuem para o ciclo da renovação da vida. [...] minha convicção [é] que nesta química reside uma possibilidade de descoberta da pedra filosofal para o trabalho de construção de novas sensibilidades ao meio ambiente. Ou seja, é nela que residem nossas chances de transformar ou, quando menos, de entender as dificuldades para a transformação do pensamento social. (Arruda, no prelo)

A definição mais consensual entre os pesquisadores do campo é a de Denise Jodelet (2002, p.22): "As representações sociais são uma forma de conhecimento socialmente elaborado e compartilhado, com um objetivo prático, e que contribui para a construção de uma realidade comum a um conjunto social".

A fluidez de conceituação da representação social, com seus múltiplos enunciados, é alvo fácil da crítica. Esta também ataca o fato de que a teoria propõe metodologias variadas e pouco amarradas. Moscovici costuma responder a tais críticas afirmando tratar-se de uma fluidez proposital, que visa permitir desenvolver a teoria e a criatividade dos pesquisadores, na medida em que o interesse maior seria a descoberta e não a verificação, a comprovação. Ao mesmo tempo, ao trabalhar com essa teoria, tentar transmiti-la a pesquisadores iniciantes, percebe-se que a representação social, na interface da psicologia e da sociologia, é uma alternativa de grande plasticidade, que busca captar um fenômeno móvel, por vezes volátil, por vezes rígido, cuja complexidade reforça a dificuldade da sua captação. Perceber uma representação social é fácil, mas defini-la, nem tanto.

Jodelet lembra que a representação social deve ser estudada articulando elementos afetivos, mentais e sociais, e integrando, ao lado da cognição, da linguagem e da comunicação, as relações sociais que afetam as representações e a realidade 
material, social e ideal (das idéias) sobre a qual elas vão intervir (Jodelet, 2002). Ela sugere que, para abarcar o conjunto de componentes e relações contidos na representação social, vista como saber prático, é preciso responder a três perguntas fundamentais: Quem sabe, e a partir de onde sabe? $\bigcirc$ que e como se sabe? Sobre o que se sabe, e com que efeito?

Estas três perguntas revelam três planos, que ela sistematizou como: I) as condições de produção e de circulação das representações sociais; 2) os processos e estados das representações sociais; e 3) o estatuto epistemológico dessas. Este último tem a ver com a relação da representação e o real. Desde o estudo da aparição da psicanálise na vida social francesa, feito por Moscovici, passando pelo estudo de Jodelet (1989) sobre o convívio de uma população rural com doentes mentais que viviam e trabalhavam na comunidade, fica evidente que a representação social é um modo de conhecimento sociocêntrico, que segue as necessidades, os interesses e desejos do grupo, o que introduz uma certa "decalagem" com relação ao objeto em construção. Assim, quando percebemos esta espécie de defasagem entre o objeto e sua representação, significa que estamos diante da marca grupal/cultural impressa no processo de construção da representação. $\bigcirc$ que aparece como uma distorção, modifica a organização ou o sentido do objeto para adaptá-lo aos desejos e necessidades de quem representa, como já explicava Festinger na dissonância cognitiva. A subtração de elementos, por sua vez, costuma ocorrer porque sua inclusão se torna difícil, por causa dos aspectos normativos ou valores de quem representa, como no caso da representação da psicanálise, que elimina a libido em virtude da sua associação com a sexualidade, ainda um tema difícil no momento da pesquisa. A suplementação é o acréscimo ao objeto representado de atributos ou conotações fornecidos pelo envolvimento ou imaginário do sujeito. Joffe brinda-nos com um excelente exemplo nos seus estudos sobre a Aids. A autora identifica em vários sujeitos a explicação da Aids pela teoria da conspiração: segundo africanos e segundo homossexuais, seria uma doença inventada em laboratório, visando destruir certos grupos marginalizados (Joffe, 1994). Mas o que esta reflexão a respeito do estatuto epistemológico das representações aponta é, também, mais do que o tipo de "alteração" que a representação introduz com relação ao objeto, o interesse de observar como e por que acontecem essas modificações, o que elas indicam, e como elas constituem a representação, dando-lhe um sentido de verdade e uma eficácia simbólica.

Uma vez mais, os teóricos da representação social revelam o quanto o pensamento dito ingênuo veicula significado e merece atenção. 
O segundo plano, o dos processos e estados da representação social, que a caracterizam como saber social, conduz ao estudo de fenômenos de ordem cognitiva, orientada pelas marcas sociais e as condições da sua gênese. Tal estudo apóia-se no conteúdo dessas representações e se dá baseado no suporte desses conteúdos: a linguagem, contida em documentos, práticas, falas, imagens e outros. O estudo dos conteúdos implica assim abarcar o campo da representação social, ou seja, a totalidade de expressões, imagens, idéias e valores presentes no discurso sobre o objeto, segundo Jodelet (2002). A noção de campo da representação implica entendêla como um campo estruturado de significações, saberes e informações.

Temos aqui, então, uma forma de abordagem das representações sociais, denominada dimensional, por abarcar as dimensões da representação - seu campo estruturado, a atitude que ela carrega e que lhe dá sua coloração afetiva, e o componente de informação que ela contém. Essa abordagem também é chamada processual (Banchs, 1998; Arruda, no prelo), genética ou dinâmica, ao preocupar-se centralmente com a construção da representação, sua gênese, seus processos de elaboração, e trabalha com os aspectos "constituintes da representação - informações, imagens, crenças, valores, opiniões, elementos culturais, ideológicos etc"., como diria Jodelet (2002, p.38). O estudo complementa-se com a busca do princípio que estrutura esse campo como um sistema, seus organizadores socioculturais, atitudes, modelos normativos ou esquemas cognitivos. A coleta de material para este tipo de enfoque geralmente é feita com metodologias múltiplas, que podem ser entrevistas, questionários, observações, pesquisa documental e tratamento de textos escritos ou imagéticos. Sua abrangência tenta capturar os diversos momentos e movimentos da elaboração da representação, embora dificilmente se possa abarcar todos eles em uma única pesquisa. Até hoje, o único exemplo de tal proeza foi o trabalho de Denise Jodelet ( 1989 ) sobre a representação da loucura, já mencionado.

A representação social, contudo, além de ser estudada como campo estruturado, também pode ser focalizada como núcleo estruturante, no qual o campo é abordado como campo semântico, conjunto de significados isolados por meio de diferentes métodos de associações de palavras. Trata-se de identificar as estruturas elementares que constituem o cerne do sistema da representação em torno das quais ele se organiza - um sistema constituído pelos seus elementos centrais e periféricos.

Assim, busca-se também, e prioritariamente, o princípio de organização da representação, seu núcleo central, aquele que apresenta maior resistência e dura- 
bilidade. Sua franja, os elementos periféricos, são aqueles que fazem a interface com as circunstâncias em que a representação se elabora e os estilos individuais de conhecer, podendo apresentar maior grau de variação e menor resistência. $\bigcirc$ grupo de estudiosos que inaugura a perspectiva do núcleo central (Claude Flament, Jean Claude Abric e outros) trouxe, além da sua contribuição teórica, uma resposta às críticas relativas à metodologia, ao propor estratégias metodológicas específicas para o estudo do núcleo central ${ }^{2}$. Os elementos pertencentes ao núcleo central seriam mais facilmente detectáveis por meio de técnicas de associação livre de palavras. O maior índice de preferência e a maior prioridade na ordem das evocações, durante os testes de associações livres, seriam seus indicadores. A combinação desses dois aspectos revela o conjunto de itens que configuram o coração da representação ${ }^{3}$.

Uma terceira linha de abordagem das representações situa-se na Escola de Genebra, capitaneada por Wilhem Doise (1986). Aqui temos um peso ainda maior dado aos processos como o de ancoragem, tomando as determinantes sociais como fundamentais, e buscando encontrar o princípio organizador das representações a partir dessa perspectiva mais sociologizante. Como a teoria do núcleo central, cabe ressaltar, as escolas de pesquisa em representações sociais na perspectiva psicossociológica não se vêem exatamente como antagonistas, e sim como frutos da grande teoria de Moscovici, como afirma Doise: são esforços de aplicação e aprofundamento, cujas características as tornam mais adequadas ou mais interessantes segundo o objeto e o objetivo que se tenha para pesquisar.

Voltando aos planos do estudo da representação delineados por Jodelet (2002), tomemos o que ainda nos falta mencionar, que poderia ser considerado o chão da representação: as condições da sua produção, ou seja, as grandes responsáveis pela possibilidade de explicação, de interpretação do sentido que os grupos atribuem ao objeto representado. Os autores da teoria afirmam que toda representação se origina em um sujeito (individual ou coletivo) e se refere a um objeto. Jodelet sintetiza a idéia: toda representação é representação de alguém e

2 A obra de Celso Sá $(1994,1998)$ traz uma excelente apresentação desta abordagem em português, para os pesquisadores iniciantes e para os especialistas.

3 Os especialistas denominam controle de centralidade a aplicação de estratégias para revelar o conjunto de itens que configuram o coração da representação: para assegurar que aqueles são realmente os elementos que não podem deixar de compor o núcleo central da representação, técnicas que permitirão verificações estatísticas são previstas na coleta de dados. 
de alguma coisa. Toda representação se refere a um objeto e tem um conteúdo. E o "alguém" que a formula é um sujeito social, imerso em condições específicas de seu espaço e tempo. A autora propõe então três grandes ordens de fatores a serem levados em conta como condições de produção das representações: a cultura, tomada no sentido amplo e no mais restrito, a comunicação e linguagem (intragrupo, entre grupos e de massas), e a inserção socioeconômica, institucional, educacional e ideológica.

As condições de produção da representação afirmam com veemência a marca social das representações, assim como seu estatuto epistemológico marca a sua função simbólica, e os processos e estados, o seu caráter prático. Vemos dessa forma como a representação social encadeia ação, pensamento e linguagem nas suas funções primordiais de tornar o não-familiar conhecido, possibilitar a comunicação e obter controle sobre o meio em que se vive, compreender o mundo e as relações que nele se estabelecem. Moscovici afirma :

.... representação social é um corpus organizado de conhecimentos e uma das atividades psíquicas graças às quais os homens tornam a realidade física e social inteligível, se inserem num grupo ou numa relação cotidiana de trocas, liberam o poder da sua imaginação. (Moscovici, 1961, p.27-28)

Em resumo, ao ser produção simbólica destinada a compreender e balizar o mundo, ela provém de um sujeito ativo e criativo, tem um caráter cognitivo e autônomo e configura a construção social da realidade. A ação e a comunicação são seu berço e chão: delas provém e a elas retorna a representação social.

\section{ÚLTIMAS CONSIDERAÇÕES}

Para encerrar esta breve panorâmica, falta retomar uma última vez as pontes entre a teoria da representação social e as teorias feministas. Sem desconhecer que as teorias feministas são variadas, talvez não seja abusivo considerar que elas têm como ponto comum a proposta de conhecimento que passa pela crítica do pensamento binário, do reducionismo, da crença na neutralidade da ciência. Esta, contudo, não é uma exclusividade do projeto epistemológico das teorias feministas, razão pela qual a discussão sobre a existência ou não de uma epistemologia feminista se prolonga. Com efeito, o projeto epistemológico da teoria da representação social também parte dessas críticas. A crítica da ciência, que ataca o viés de gênero pelo lado das feministas, ampara-se na perspectiva subjetivista, baseada na experiência, no chamado paradigma do standpoint-as mulheres conheceriam de forma 
diferente da dos homens devido à sua condição social (Farganis, 1992) e biológica (Bordo, 1992). Não se trataria de uma visão simplesmente essencialista, mas sim de que "o conteúdo e a forma do pensamento, ou as idéias e processos pelos quais essas idéias são geradas e compreendidas são afetados por fatores sociais concretos, e o gênero é um deles"(Farganis, 1992, p.208). Haraway (1991) lembra que não há um único standpointfeminista e reafirma o "conhecimento situado" como a base da objetividade feminista, que integra conceitos cognitivos e contextuais da produção científica.

A denominada epistemologia feminista, ao proclamar a experiência das muIheres como característica de uma cultura específica, torna-a uma modalidade de saber local e propõe para a agenda feminista uma antropologia da cultura moderna, como Moscovici com as representações sociais. Planta porém nela o germe de um novo "centrismo", o ginocentrismo, ao partir do privilégio epistêmico das mulheres. No projeto das representações sociais, o reconhecimento dos saberes locais coloca-os como fontes de especificidade sem atribuir-lhes um privilégio que os hierarquize.

A raiz dessa diferença, e de outras entre os dois projetos, poderia situar-se nas suas origens. A teoria feminista, ao partir de um projeto político, pretende ir além da mera compreensão dos fenômenos de opressão e subordinação. Compreendê-los torna-se uma atividade-meio para a meta de transformação das relações entre os gêneros. A experiência feminina, tomada como um sistema cultural, é colocada no mesmo pé que o senso comum, esse saber baseado na confiança que se tem do seu valor e da sua validade, como disse Geertz (1997). Ou seja, de ocultada e desconsiderada pelas teorias dominantes, ela passa a ser considerada como fonte de conhecimento e deve ser desvendada, propagando-se o que tem de interessante. Isso pode até "significar novas formas de examinar problemas antigos, principalmente os que se relacionam com a maneira como a cultura é articulada e fundida..." (Geertz, 1997, p. I 16). Já o projeto da teoria das representações sociais, embora oriundo da profundeza da realidade cotidiana, resgata o senso comum enquanto compartilhado pela sociedade como um todo, entretecido com nossa linguagem e constitutivo de nossas relações e habilidades (Moscovici, Markova, 1998) ${ }^{4}$, mas não se coloca, nem o coloca no terreno político. A questão do poder, dessa forma, é um ponto nodal no primeiro, mas não no

4 Moscovici criará uma outra teoria para aproximar-se do que seria uma discussão relacionada com o poder: a psicologia das minorias ativas, que não abordarei aqui (Moscovici, 1979a). 
segundo. $\bigcirc$ primeiro traz embutida uma teoria da ação, enquanto o segundo é uma proposição analítica.

A questão da racionalidade como fulcro da modernidade é retomada por ambos projetos, embora com interesses diversos. Tanto o pensamento feminista quanto o moscoviciano atacam o postulado da redutibilidade, que proclama um modelo único de racionalidade e menospreza as demais, seja a dos "primitivos" (Lévy-Bruhl, 1938), a das crianças (Piaget, s.d., 1977) ou das mulheres (Gilligan, 1982). Apenas, tendo em vista os aspectos abordados acima, o feminismo colocase como crítica da modernidade, seu projeto é muito abrangente e sua vocação para a ação leva-o a atuar nesse sentido, enquanto o projeto da teoria das representações sociais não se dedica a esse objetivo; seu escopo é mais reduzido, embora não deixe de ser uma visão crítica também. É sobretudo a própria psicologia que está posta em questão pelo projeto das representações sociais, que é um projeto de psicossociologia do conhecimento. Sua intenção, como já foi dito, é compreender a química da incorporação das novidades, da mudança das teorias em saber do senso comum, da construção do pensamento social. Mutatis mutandis, ele vai propor metodologias igualmente dissidentes dentro da área, assim como os estudos feministas o fazem em suas respectivas áreas.

Assim, para encerrar, posso sintetizar o que estive tentando desenvolver, com a afirmativa de que a teoria da representação social é um produto típico dos nossos tempos e da transição paradigmática, tanto quanto as teorias feministas e outras que, a sua maneira, surgem como novas ferramentas conceituais para analisar ângulos da realidade postos em pauta por novos olhares, provindos das lutas dos movimentos sociais, da criatividade e dos questionamentos no seio da ciência. Sua contribuição é inegável para atravessar essa quadra, sem perder de vista que, como toda produção cultural, também ela será modificada e superada por outras, que a complementarão e corrigirão com o passar do tempo e o avanço do conhecimento. Mas, por enquanto, as duas teorias oferecem um bom instrumental para a compreensão do ser humano na sua complexidade e abrem portas para avançarmos na caminhada para futuras angulações. Fica uma pergunta, a ser retomada em outra ocasião e também por outros(as) respondentes: por que, diante de tantas afinidades, a aproximação entre elas não é maior? 


\section{REFERÊNCIAS BIBLIOGRÁFICAS}

ARRUDA, A. Uma abordagem processual das representações sociais sobre o meio ambiente. In: ARRUDA, A. (org.). Olhares sobre o contemporâneo: representações sociais de exclusão, gênero e meio ambiente. João Pessoa: UFPB. (no prelo)

Representaciones y opiniones, o: jugando con la muñeca rusa. Revista AVEPSO, v. 16 n. I/3, p.3-1।, 1993.

BANCHS, M. A. Aproximaciones procesuales y estructurales al estudio de las representaciones sociales. In: CONFERÊNCIA INTERNACIONAL SOBRE REPRESENTAÇÕES SOCIAIS. México, p. 25-28 ago., 1998.

BERGER, P., LUCKMANN, T. A Construção social da realidade. Petrópolis: Vozes, 1978.

BORDO, S. R. The Body and the reproduction of femininity: a feminist appropriation of Foucault. In: JAGGAR, A. M.; BORDO, S. R. (eds.). Gender/body/knowledge: feminist reconstructions of being and knowing. New Brunswick: Rutgers University Press, 1992 , p. 13-33.

BOURDIEU, P. O Campo científico. In: ORTIZ, R. (org.). Bourdieu. São Paulo: Ática, 1983 , p. $122-155$.

DOISE, W. Les Représentations sociales: définition d'un concept. In: DOISE, W.; PALMONARI, A. Textes de base en psychologie: l'étude des représentations sociales. Lausanne: Delachaux et Niestlé, 1986, p.81-94.

FARGANIS, S. Feminism and the reconstruction of Social Sciences. In: JAGGAR, A. M.; BORDO, S. R. (eds.). Gender, body, knowledge: feminist reconstructions of being and knowing. New Brunswick: Rutgers University Press, 1992, p.207-223.

FARR, R. Representações sociais: a teoria e sua história. In: JOVCHELOVITCH, S.; GUARESCHI, P. (orgs.). Textos em representações sociais. Petrópolis: Vozes, 1994, p. 3 I -59.

FREUD, S. On the sexual theories of children. Londres: Standard Editions, 1908.

Pequena coleção das obras de Freud. Rio de Janeiro: Imago, 1976.

GEERTZ, C. O Saberlocal: novos ensaios em antropologia interpretativa. Petrópolis: Vozes, 1997.

GILLIGAN, C. In a different voice: psychological theory and women's development. London: Cambridge, 1982.

JODELET, D. Folie et représentations sociales. Paris: PUF, 1989.

Representações sociais : um domínio em expansão. In: JODELET, D. (org.). As Representações sociais. Rio de Janeiro: Eduerj, 2002, p. 17-44. 
JOFFE, H. Eu não, meu grupo não: representações sociais da AIDS. In: GUARESCHI, P.; JOVCHELOVITCH, S. (orgs.). Textos em representações sociais. Petrópolis: Vozes, 1994 , p.297-322.

HARAWAY, D.J. Simians, cyborgs and women: the reinventation of nature. New York: Routledge, |99|.

LÉVY-BRUHL,L. L'Expérience mystique et symboles chez les primitifs. Paris: Félix Alcan, 1938. MORIN, E. Por uma reforma do pensamento. In: PENA-VEGA, A.; NASCIMENTO, E. P. (orgs.). O Pensar complexo: Edgar Morin e a crise da modernidade. Rio de Janeiro: Garamond, 1999, p.21-34.

OProblema epistemológico da complexidade. Lisboa: Europa-América, 1985.

MOSCOVICI, S. Chronique des anées égarées. Paris: Stock, 1997.

Comunicação apresentada ao Colóquio sobre as Representações Sociais, Paris, EHESS, 8-10 jan. 1979.

Des représentations collectives aux représentations sociales: éléments pour une histoire. JODELET, D. (org.). Les Représentations sociales. Paris: PUF, 1989, p.62-86.

. Le Grand schisme. Revue Internationale de Sciences Sociales, v. 25, n. 4, p.479-490, 1973.

Notes towards a description of Social Representations. European Journal of Social Psychology, n. 18, p.21 1-250, 1988.

La Psychanalyse, son image, son public. Paris: PUF, I96I.

Psychologie des minorités actives. Paris: PUF, 1979a.

MOSCOVICI, S.; MARKOVA, I. Presenting social representations: a conversation. Culture \& Society, v. 4, n. 3, p.37I-410, 1998.

MOSCOVICI, S.; NEMETH, C. Minority influence. In: NEMETH, C. (org.). Socialpsychology: classic and contemporary integrations. Chicago: Rand McNally, 1974, p.217-250.

PIAGET, J. O Julgamento moral na criança. São Paulo: Mestre Jou, 1977. A Representação do mundo na criança. Rio de Janeiro: Record, s.d.

ROAZZI, A. Pesquisa básica em psicologia cognitiva e sua relação com a psicologia social. Arquivos Brasileiros de Psicologia, v. 5 I , n. I. p.23-54, 1999.

RUBIN, G. The Traffic in women: notes on the 'political economy' of sex. In: REITER, R. Towards an anthropology of women. New York: Columbia University Press, 1979, p. I 57-2 10. SÁ, C. P. A Construção do objeto de pesquisa em representações sociais. Rio de Janeiro: Eduerj, 1998. 
Núcleo central das representações sociais. Petrópolis: Vozes, 1994.

SADER, E. Quando novos personagens entraram em cena. Rio de Janeiro: Paz e Terra, 1988.

SANTOS, B. S. Introdução a uma ciência pós-moderna. Rio de Janeiro: Graal, 1989.

SCOTT, J. W. G. Une catégorie utile d'analyse historique. Les Cahiers du Grif, n. 37/38, p. $125-153,1988$.

Recebido em: abril 2002

Aprovado para publicação em: maio 2002 